\title{
Management of medical waste in Tanzanian hospitals
}

\author{
S.V. MANYELE ${ }^{*}$ and H. ANICETUS ${ }^{2}$ \\ ${ }^{1}$ Department of Chemical \& Process Engineering, University of Dar es Salaam, \\ P.O. Box 35131, Dar es Salaam, Tanzania \\ ${ }^{2}$ Ministry of Health and Social Welfare, P.O. Box 9083, Dar es Salaam, Tanzania
}

\begin{abstract}
A survey was conducted to study the existing medical waste management (MWM) systems in Tanzanian hospitals during a nationwide health-care waste management-training programme conducted from 2003 to 2005 . The aim of the programme was to enable health workers to establish MWM systems in their health facilities aimed at improving infection prevention and control and occupational health aspects. During the training sessions, a questionnaire was prepared and circulated to collect information on the MWM practices existing in hospitals in eight regions of the Tanzania. The analysis showed that increased population and poor MWM systems as well as expanded use of disposables were the main reasons for increased medical wastes in hospitals. The main disposal methods comprised of open pit burning (50\%) and burying (30\%) of the waste. A large proportion (71\%) of the hospitals used dust bins for transporting waste from generation points to incinerator without plastic bags. Most hospitals had low incineration capacity, with few of them having fire brick incinerators. Most of the respondents preferred on-site versus off-site waste incineration. Some hospitals were using untrained casual labourers in medical waste management and general cleanliness. The knowledge level in MWM issues was low among the health workers. It is concluded that hospital waste management in Tanzania is poor. There is need for proper training and management regarding awareness and practices of medical waste management to cover all carders of health workers in the country.
\end{abstract}

Key words: medical waste management, incineration capacity, hospitals, Tanzania

\section{Introduction}

Medical waste is the second most hazardous waste after radioactive waste. The improper management of medical wastes (MW) causes serious environmental problems in terms of air, water and land pollution (Manyele, 2004a). The nature of pollutants can be classified as biological, chemical and radioactive. Environment problems can arise from the mere generation of MW and from the process of handling, treatment and disposal.

Hospital-waste handling is a hazardous waste activity which requires a high standard of training. It calls for specific training that depends on the nature of the work in the hospital, the hazards and possibility of worker exposure, and the responsibilities of individual workers (US-DOE, 1996; Blackman, 1996). Training of health care workers is the core of health care waste management programmes (USDOE, 1996). The training must not only be continuous, but also comprehensive, integrated and structured with the necessary elements. To reach the qualified stage, the training must follow some of the following steps: need analysis; training administration; learning objectives development and lesson plans; site-specific training; task-specific training; and supervision.

According to Manyele (2004b), medical waste generation is high and is increasing, reaching up to $0.75 \mathrm{~kg} / \mathrm{bed}$ per day on average. Given a large number of beds throughout the country, it is obvious that medical waste requires immediate attention in Tanzania. A factor which intensifies the medical waste generation rate is the occupancy rate which is alarmingly higher in Tanzania (about 131\%) compared to other countries like Pakistani (about 76\%) (Manyele, 2004b). As a result of a wide spread in the medical waste generation rates, Tanzania has distributed the regions into two groups: priority and non priority areas, which produce above or below 800 $\mathrm{kg}$ /day, respectively.

This study emanated from a training programme on medical waste management that was carried out in Tanzania from 2003 to 2005. The purpose of this training was to introduce the health workers to the better means of managing medical waste starting from the generation point to the final disposal (cradle to grave). Meanwhile, the health workers had an opportunity to participate physically in the step-bystep construction of De Montfort incinerator so that they can construct new ones in their respective health facilities.

\section{Materials and Methods}

Data on MWM systems were collected during training sessions for health workers which were conducted from 2003-2005 in three zones (South, West and the Lake Zone) covering a total of 8 regions in Tanzania. In the Southern zone, the regions covered were Mtwara and Lindi centred in Masasi at Mkomaindo Hospital. The Western zone was centred in Tabora at 
Kitete Hospital, covering Rukwa, Kigoma and Tabora regions. The Lake regions (Mara, Shinyanga and Mwanza) were centred in Mwanza at Sekou-Toure Hospital.

The instrument of research was a self administered questionnaire which was circulated during the training sessions to collect data on existing MWM systems. The information sought to document the main causes of increased MW volumes in hospitals; nature of the waste generated and fractions that can be re-used; number and types of incinerators existing; the levels of knowledge of the respondents on the issues related to MWM (toxic gases emitted from incinerators, toxic metals released in the bottom and fly ash, differences between municipal solid waste (MSW) and MW; methods used in moving waste from the source to the disposal facilities; and incineration facilities available at the hospital.

To eliminate bias in the results, each participant was required to fill the questionnaire before the training session started. The respondents from different regions comprised of the health officers of different ranks, health attendants, incinerator operators, a contractor and an artisan.

To identify areas which need emphasis during training the knowledge levels of participants in different areas of waste management were examined. These included medical waste characterisation/ categories; exposure routes for medical wastes; definition of important terms used in medical waste management; occupational health hazards from improper hospital waste management; and emissions from medical waste incinerator (gases and heavy metals).

\section{Results}

A total of 84 respondents participated in this study which covered 8 out of 21 regions of Tanzania Mainland. Of the 84 respondents, health officers accounted for the largest proportion (41\%). Others included medical attendants $(19 \%)$, health attendants (16\%), health assistants (12\%), regional health officers $(9 \%)$, public health officers $(1 \%)$, nurse/ midwives (1\%) and waste handlers (1\%). Only a few females $(\mathrm{N}=12)$ were among the participants; and they were from Mwanza, Shinyanga and Lindi. Mwanza was the only region represented by a large number of participants (22).
The increase in population and poor management practices were mentioned as the most important factors contributing to increased medical wastes. Others included presence of more disposables, visitors, lack of incinerators, high mobility into towns and low quality of incinerators in use (Figure 1). However the respondents' awareness on the contributing factors differed from one region to another.

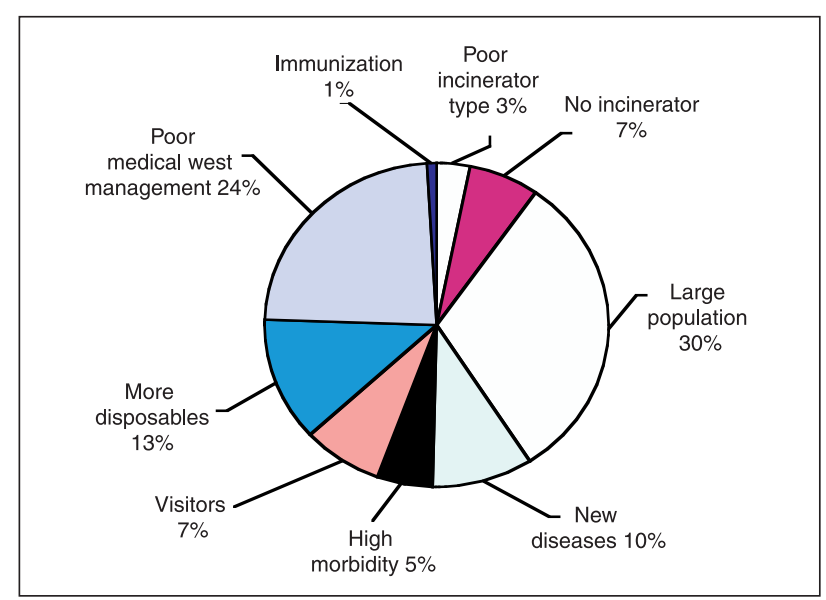

Figure 1: Reasons for increased MW volumes in Tanzanian Hospitals

The number of personnel in the department responsible for medical waste management differed from one hospital to another (Figure 2). Lindi, Mwanza and Kigoma had more labour power to deal with medical waste than others.

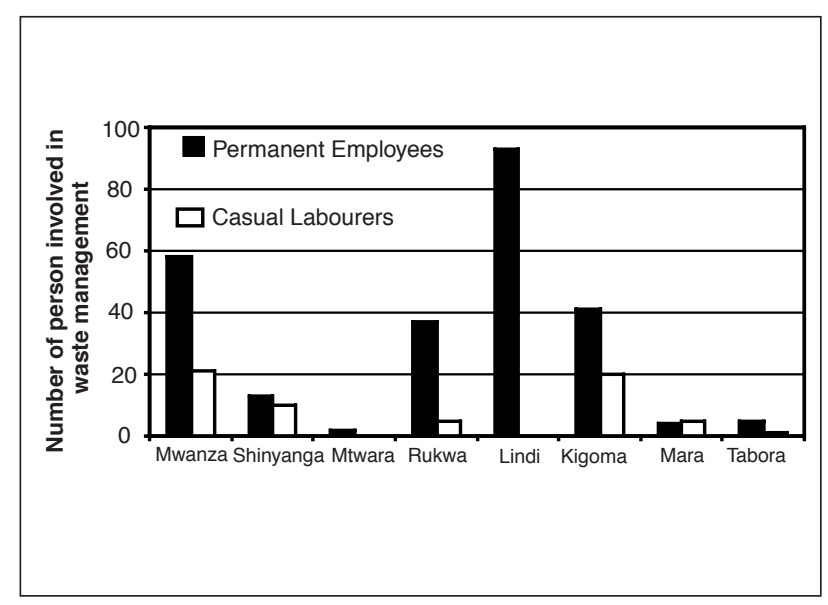

Figure 2: Average number of personnel in the departments responsible for MW management 
Results on the respondents' knowledge on the differences between medical waste and municipal solid waste (MSW) are summarised in Figure 3. In all regions the overall knowledge on MW before training was below $50 \%$. The lowest knowledge levels were observed among respondents from Mtwara and Lindi regions. It was further observed that the respondents were not aware of the actual differences between MSW and MW, other than conceived perception of diseases transmission by poor management of MW.

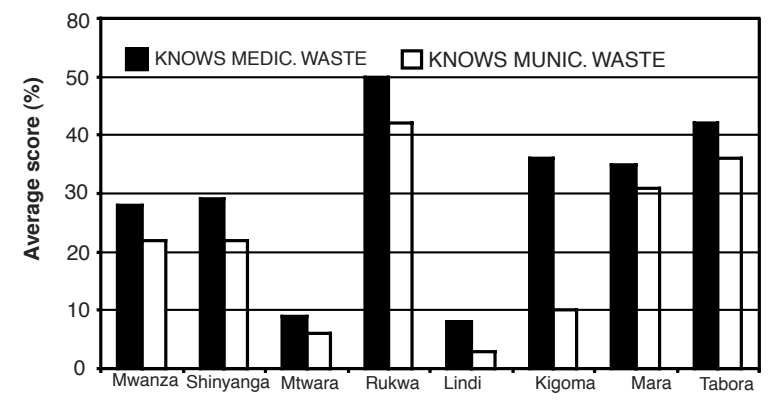

Figure 3: Knowledge on medical waste and Municipal solid waste

The respondents were also requested to state the components of the hospital waste that can be re-used. The response given included bottles $(18 \%)$, boxes $(17 \%)$, general plastics $(17 \%)$, glass $(14 \%)$, plastic bags $(11 \%)$, containers $(10 \%)$, metal equipment $(8 \%)$ and waste papers $(5 \%)$.

The respondents from Mwanza indicated stronger preference on on-site incineration (that is, within hospital premises) over off-site incineration (outside the hospital premises). Relatively lower preference for off-site was reported by participants from Shinyanga, Mtwara and Lindi. Respondents from other regions did not show any preference on off-site incineration at all. Several reasons were given by respondents for preferring on-site than off-site incineration facilities (Figure 4). These included easy of managing $\mathrm{MW}$; on-site incinerators were closer to the generation point; easy of transportation of MW from source to the treatment site; and avoiding spread of MW during transportation. Other respondents still believed that MW is not movable while others were interested in on-site incineration as long as there was enough space. One important factor, which the trainees did not put forward, was the cost analysis for the treating MW on-site versus off-site.

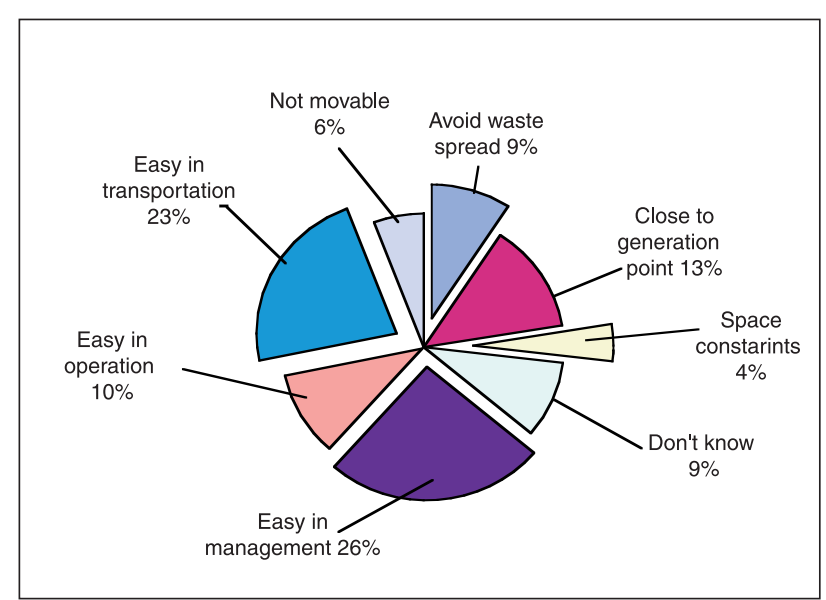

Figure 4: Reasons for preferring on-site versus off-site incineration of medical waste

Twelve ordinary incinerators (made of red bricks) existed in the regions before the introduction of De Montfort incinerators (Figure 5). Data from seven hospitals showed that when the existing incinerators were not working, most hospitals dump the sharp waste in pit latrines and secure pits or burry the waste. Lindi region had four ordinary incinerators made of firebricks followed by Kigoma and Tabora (3 units) each. Both Mwanza and Rukwa had only 1 unit each. Shinyanga, Mtwara and Mara regions did not have any such unit. The analysis shows also that there has been very low incineration capacity before 2002, given a very small number of incinerators existing before introduction of the De Montfort.

Use of dust bin accounted for $71 \%$ of the methods of MW movement used in the hospitals. Others included use of wheelbarrow (18\%) and boxes (7\%) (Figure 5). The use of dust bins corresponded to the fact that most hospitals treated their waste by burning in the open pits. In very few cases plastic bags were used (about 4\%), which means that the wheel burrows carry waste either in small container or openly. The lack of plastic bags and improper waste movement from sources to treatment sites was mainly attributed to lack of budget for plastic bags. The fact that boxes were used in even fewer cases signifies further that MW was transported openly from the source to the incinerator in the dustbins. 


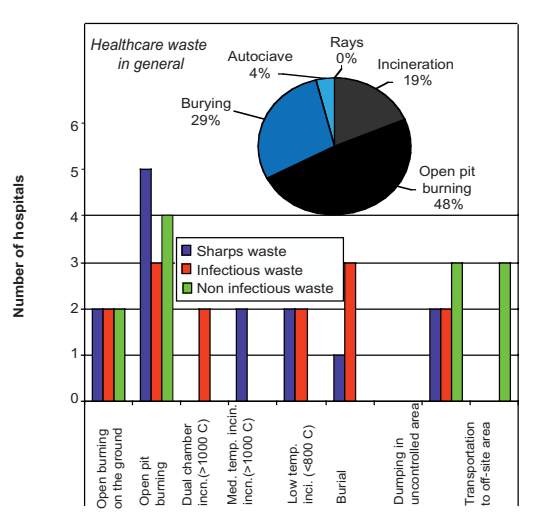

Figure 5: Disposal methods for medical waste in hospitals in Tanzania

The main disposal methods for MW in the hospitals comprised of open pit burning, burying and incineration. A large number of the hospitals used open pit burning for MW (48\%), which is not advisable. Very few hospitals (4\%) were reported to use autoclave for MW treatment, due to the fact that this is an expensive technology.

The management of sharps waste in health facilities was directly connected to blood-borne disease transmission (HIV, Hepatitis B and C viruses). The best way to prevent workers' exposure to such infections was by provision of personal protective equipment (PPE). During this survey, the respondents were asked if they had such items in their facilities. Six of the hospitals had aprons, five had gloves and boots, and only two had masks. Two of the hospitals had none of the items required for personal protection. Goggles were not available in all the eight regions.

\section{Discussion}

Our results indicate that most health workers have low knowledge on medical waste management in Tanzania. Similar observations have been reported in other developing countries such as Palestine (Massrouje, 2001), India (Pandit et al., 2005) and Pakistani (Rasheed et al., 2005). There is a need for on-job training on MWM and special training for new employees to cover this gap. All new employees in the medical/health sector need to attend a course on medical/hazardous waste management to equip them with the knowledge to tackle problems associated with MWM in their workplaces.

In principle, the responsible ministry must provide training for all strata or ranks of health-care workers because they are involved in one way or the other in the MWM (Manyele et al., 2003). However, the results from this study indicate that some of the important ranks were not fully involved, because most of the respondents were health officers, medical attendants and health attendants. Thus, the first training programme was not totally effective because some important cadre involved in MW generation points, were not involved. Not including some of the cadres in such an important training programme will lead to weaknesses during the implementation of the MWM programme.

Interestingly, only a smallest percentage of the participants were nurses and/or midwives. One expects this cadre to occupy a large portion during training because they are directly involved in the waste generation points (wards, theatres). It is important that training also covers this important cadre, with emphasis on segregation and packaging at the respective generation points without much attention to the incineration. Another cadre which is important but did not show up in the chart is the pharmacist. Beside packaging materials that cause waste generation from the pharmacy, there are also expired drugs entering the MW stream. Pharmacists need to learn more on the proper practices on waste minimization like good house keeping, inventory tracking and methods of staying organized. Such lessons can be included in the existing training courses.

It is important for the health-care crew to understand the hazards related to MW. These hazards can be categorized as biological or infectious hazards (bacteria, such as tuberculosis, and viruses, such as HIV, Hepatitis B and C); chemical hazards (medications, solutions, or gases, such as ethylene oxide, formaldehyde, glutaraldehyde, waste anaesthetic gases, nitrous oxide, chemotherapeutic agents, laser smoke and aerosolized medications such as pentamidine); and physical hazards (ionizing radiation, lasers, noise and electricity).

Pathogens present in the MW can enter and remain in the air within the hospital for a long period, in the form of spores or as pathogens (http:// kspcb.kar.nic.in/BMW/environmental.htm). This can result in hospital-acquired infections (nosocomial infections) and other occupational health hazards. Also, patients and their attendants have a chance of contracting infections caused by airborne pathogens or spores. However, there is very limited statistics available relating occupational health with workers' hospital-acquired infections. The only publicized health hazard to workers is the spread of disease from contaminated sharps (medical equipment used to penetrate skin and muscles such as needles and blades) (Rutala \& Mayhall, 1992). When waste that has not been pre-treated is dumped openly, pathogens can enter the atmosphere. These pathogens can find their way to drinking water, foodstuffs or soil.

Chemical pollutants that cause outdoor air pollution have two major sources: open burning and incinerators. The presence of plastics and hazardous chemicals in the waste will generate harmful gases 
- such as oxides of sulphur, oxides of nitrogen, carbon dioxide, etc.), and suspended particulate matter which may contain heavy metals. When these gases are inhaled, they can cause respiratory diseases. Air pollution control devices should be used for waste combustion technologies which produce toxic emissions.

The occupational health effects of medical waste depend on the duration of exposure and the dose of toxic components that enters the worker's body from the waste. Unmanaged hospital waste constitutes a hazard to the personnel because it also contains toxic chemicals ready to enter the human body through different routes of exposure (Griffin, 1990). Due to the structure of the human lung, the body's retention capacity for airborne particulates that carry toxic chemicals and pathogens is highly dependent on particle size.

Dermal absorption can be enhanced by scratched, broken, roughened or abraded surfaces of the skin on the ankles, hands, neck or facial areas. The worker's face or hands are the most affected skin areas. Watersoluble toxic chemicals can be absorbed throughout the body since the human metabolism operates on a water-based chemistry. Therefore, drinking and eating in hospitals must be done in well-controlled areas. This issue is not well addressed in most Tanzanian hospitals.

The chemical poisons in hospital waste can affect different parts of the body; for instance, hepatoxic (e.g. carbon tetrachloride, tetrachloroethane), nephrotoxic (e.g. halogenated hydrocarbons); haematopoietic (benzene, phenols); and neurotoxic (e.g. methanol, metals, organometallics) and anaesthetic agents (e.g. ethyl ether, esters, acetylene hydrocarbons) (Griffin, 1990).

When MW is treated by incineration technology, various compounds are usually emitted. These include $\mathrm{NO}, \mathrm{SO}_{2}, \mathrm{CO}, \mathrm{CO}_{2}, \mathrm{HCl}$, dioxins and furans. The compounds have impacts on human health and the environment (Manyele et al., 2003). During incineration, heavy metals such as mercury, lead, arsenic and cadmium are also formed which attaches themselves to the fly ash and bottom ash.

Unlike the findings of our study, all health officers are expected to be familiar with both medical and municipal waste management, in terms of composition, physical characteristics and heating values, biological and chemical characteristics. The MW is not very different from the MSW, except in some details. There are items found in both MSW and MW like plastics, glass and food waste. Such items are very challenging in waste management. In case of MW, food remains and glass adversely affect the incinerator performance, while plastics pose a threat to the environmental health and safety of the personnel during MW incineration. Items not commonly found in MW are tires, construction and demolition wastes and pathological wastes. In many cases, there is a high percentage of recyclables in the MSW than in the MW for reasons of infectious nature.

Recycling of MW means sorting items for use and re-use together with reclamation. In addition to reduction of waste volume at the source, separation practices like segregation of materials as they are generated based on their characteristics that target particular material/waste for recycling and the most appropriate treatment method, can lead to more environmentally sound MW management. Any health-care facility should be able to plan and develop comprehensive waste management programmes, of which recycling is an integral part.

There is speculation about whether the exemption from tracking requirements for MW treated on-site (which meet the specified regulatory requirements) would encourage use of on-site incineration. This may not occur, given that other conditions (e.g., increased expense and/or space limitations to expand existing facilities, limited onsite expertise in waste management, etc.) may provide strong incentives for off-site treatment. A trend toward more off-site incineration may occur if changing requirements for waste management make it more advantageous to the medical facilities for off-site than on-site incineration. Yet, health-care facilities still tend to favour on-site treatment to gain control over the ultimate disposal and can thereby limit their liability more easily. In addition, properly designed, operated, and maintained off-site facilities can meet emission standards and provide viable waste disposal option.

The lower preference for off-site incinerator facilities is backed up by the fact that there exist no commercial incineration facilities in Tanzania. This concept needs to be emphasized because there is a possibility of having commercial units for regional MW incineration, which may be privately owned and/ or operated, by a number of generators. It should be conceivable that as with MSW incineration, some of these facilities might be run by municipality or by a private company with a number of MW generators (Manyele, 2004a).

The variable nature of the equipment design, size, and add-on pollution control equipment make it impractical to identify the typical cost of treating MW by incineration (Guttman, 1990; Spurgin, 1990). Incineration cost can vary by more than 500 percent and wide cost ranges have been identified (Guttman, 1990; Spurgin, 1990). The uncontrolled incineration costs are obviously lower than controlled incineration (ARB, 1990). It is generally believed that incineration is a more costly alternative than most non-incineration treatment alternatives; some estimates find autoclaving to be 30 percent of the cost of incineration (Spurgin, 1990), but final disposal costs for autoclaved waste can add up to the total cost. 
Relative health risks associated with the combustion of MW continue to be debated as data remains limited. A thorough examination of health and environmental risks posed by different pollutants is important (Barton et al., 1989; ARB, 1990). The intention here is to identify those pollutants of primary concern in MW incineration because of their potential human health and environmental impacts.

It is important to note that waste movement from the source to the disposal site can affect the MW management system if not well planned. Before the containers are filled in the generation points, MW must be stored properly in closed containers, preferably buckets inserted with plastic bags. The bags should then be closed when full, ready for transport to the treatment site.

How the waste is transferred from the source to the incinerator, for example, is an important issue. This depends on the treatment methods as well. For instance, carrying waste in a dustbin is not advisable if the waste is to be fed into the combustion chamber of De Montfort incinerator, because the operator will have to drain and distribute the waste into small parts before it can be fed into the chamber.

Although the study covered only about half of the regions in Tanzania, the results provide a representative picture of the actual situation all over the country. The number of trainees used in this survey is good enough to give reliable results, based on the fact that it was made up of health-care workers of different cadres responsible for MWM. The fact that the study was conducted during the training sessions was likely to be cost-effective in terms of resources which would have been required to visit individual hospitals at different times. Moreover, besides filling the questionnaires and providing data, the exercise was a learning process for the participants. The training conducted by the Ministry of Health in 2003 enabled workers to recognize health and safety hazards, and to prevent further exposure to hazards posed by hospital waste. However, the training focused only on those handling hospital waste and health officers, while the waste generators (nurses and medical doctors) were not involved. For this reason, a comprehensive integrated health and safety training programme has been developed at the University of Dar es Salaam to provide a cost-effective means of meeting health care waste management needs in Tanzania. There is an immediate and urgent need to train all health workers to adopt an effective medical waste management practices.

\section{Acknowledgements}

The authors would like to convey sincere gratitude to the World Health Organization and Ministry of Health for financial support for training. Messrs Y. Mwita, H. Mahige, F. Msese, E. Msarika and B. Ngaeje are thanked for their assistance during data collection.

\section{References}

ARB (1990) Proposed Dioxins Control Measure for Medical Waste Incinerators. State Report, State of California Air Resources Board, Stationary Sources Division, Sacramento, CA.

Auber, J. \& Drum, D. (1990) Best Controlled Technologies for Regional Biomedical Waste Incineration. 83 ${ }^{\text {rd }}$ Annual Meeting of the Air and Waste Management Association. Pittsburgh, PA,

Barton, R., Hassesll, G., Lanier, W. \& Seeker, W. (1989) State of the Art Assessment of Medical Waste Thermal Treatment. Energy and Environmental Research Corporation.

Blackman, W.C. (1996)Basic Hazardous Waste Management. $2^{\text {nd }}$ Edition. Lewis Publishers, Inc., Michigan.

Griffin, R.D. (1990) Principles of Hazardous Materials Management. Lewis Publishers, Inc., Michigan, USA.

Guttman, R. (1990) Survey and Analysis of Costs of Disposing of Medical Wastes. OTA Contract Report.

Manyele, S.V. (2004a) Effects of Improper HospitalWaste Management on Occupational Health and Safety. African Newsletter on Occupational Health and Safety 14, 30-33.

Manyele, S.V. (2004b) Medical/hazardous Waste Management for Practitioners. Course notes for the BICO Professional Development Program, Prospective College of Engineering and Technology, University of Dar es Salaam, January 2004.

Manyele, S.V., Anicetus, H. \& Bilia, M.H. (2003) Globalization and its Effects on Medical Waste Management in Tanzania. IET Journal, Conference Proceedings, $4^{\text {th }}-5^{\text {th }}$ December, 2003, AICC, Arusha.

Massrouje, H.T. (2001) Medical waste and health workers in Gaza governorates. East Mediterranean Health Journal 7, 1017-1024.

Pandit, N.B., Mehta, H.K., Kartha, G.P. \& Choudhary, S.K. (2005) Management of bio-medical waste: awareness and practices in district of Gujarat. Indian Journal of Public Health 49, 245-247.

Rasheed, S., Iqbal, S., Baig, L.A. \& Mufti, K. (2005) Hospital waste management in the teaching hospitals of Karachi. Journal of Pakistan Medical Association 55, 192-195.

Rutala, W.A. \& Mayhall, C.G. (1992) Medical Waste. Infectious Control and Hospital Epidemiology 13, 38-48.

Spurgin, R. (1990) Medical waste treatment Technologies. Contract Report for the Office of Technology Assessment. Spurgin \& Associates.

US DOE (1996) Office of Environmental Management. US Department of Energy. 